\title{
Career Readiness Driven by Sequential CUREs
}

\author{
Patrick J Killion \\ University of Maryland \\ pkillion@,umd.edu \\ Ian B Page \\ University of Maryland \\ Alexis Boytim \\ University of Maryland
}

\section{Introduction}

The University of Maryland (UMD) First-Year Innovation \& Research Experience (FIRE) was launched in 2014 (Killion \& Page, 2016; Killion, Page, \& Yu, 2019; The University of Maryland, n.d.). The initial focus of the program was to provide authentic faculty-led research experiences, mentorship, and accelerated opportunities for first-year undergraduate students from a wide range of academic backgrounds. The program now impacts over 600 new first-year freshmen and transfer students annually through the operation of more than 15 independent research streams representing the natural, social, technological, and applied sciences.

FIRE is a university-wide program based on the Freshman Research Initiative (FRI), a largescale, STEM-centered undergraduate research program established in the College of Natural Sciences at The University of Texas at Austin in 2006 (Beckham, Simmons, \& Stovall, 2015; Rodenbusch et al., 2016; University of Texas at Austin, n.d.). Students participate in FIRE through the completion of a sequential three-semester course-based undergraduate research experience (CURE). The sequential nature enables students to cumulatively build personal and professional outcomes through a threesemester process of research preparation (FIRE Semester 1), training (FIRE Semester 2), and accomplishment (FIRE Semester 3). Optional mid-program (FIRE Summer Fellowships) and postcompletion (FIRE Next Steps) opportunities allow students to develop leadership capacities in addition to their research training.

\section{Extending the Impact: Career Readiness}

Research-Centered Assessment of Program Impacts \& Outcomes

The outcomes targeted by FIRE align broadly with several decades of scholarly research that has characterized the wide range of personal and academic outcomes for students in undergraduate research experiences (Auchincloss et al., 2014; Brownell et al., 2012; Elgin et al., 2016; Linn et al., 2015; National Academies of Sciences, Engineering, and Medicine, 2017). The FIRE program was developed to provide students the central features considered essential to CUREs. These include the use of authentic and contemporary research methods, the capacity to engage in the process of creating new knowledge, the engagement of work broadly relevant to the world around us as well as the specific discipline engaged, and the ability to repeat or revise aspects of the research to address unexpected challenges (AAAS, 2011; Auchincloss et al., 2014; National Academies of Sciences, Engineering, and Medicine, 2017). 


\section{Transitioning to a New Framework - Career Readiness}

Through years of operation and reflective conversations with participating students and parents, it was determined that additional levels of professional relevance were needed to augment the researchcentered program experiences and outcomes targeted. In 2019-20 the FIRE program engaged in an in-depth process of curricular and assessment reform to support the measured attainment of capacities directly connected to student professional development.

The FIRE program adopted the National Association of Colleges and Employers Career Readiness competencies (National Association of Colleges and Employers, n.d.). These include student capacities to use sound reasoning to analyze issues and make decisions and overcome problems (critical thinking); articulate ideas clearly (communication); build relationships representing diverse cultures, races, genders, religions, and viewpoints (collaboration); develop accountable and effective work habits (professionalism); and leverage the strengths of others to achieve common goals and use interpersonal skills to coach and develop others (leadership).

\section{Professional Development \& Career Readiness - A Student Perspective}

\section{Alexis Boytim - FIRE Student, Peer Mentor, Career-Ready Graduate}

Alexis Boytim, a co-author of this manuscript, started at UMD in the fall semester of 2014 and joined the FIRE Sustainability Analytics research stream in the spring semester of 2015. After completing the FIRE course sequence, Boytim served as a FIRE peer mentor through FIRE's Next Steps program during the calendar year 2016. During this period of time, Boytim was instructed and mentored by Page, the founding research educator for FIRE Sustainability Analytics.

\section{Degree-Relevant Research in the Social Sciences}

Boytim started at UMD as an environmental science and technology major in the College of Agriculture and Natural Resources. She graduated in the spring semester of 2018 with a Bachelor of Science in Environmental Science and Technology with a concentration on Environmental Health and a minor in International Development and Conflict Management.

From her start at UMD, participation in the FIRE program accelerated her connection with her chosen major and academic department by providing her a deeply relevant research home: FIRE Sustainability Analytics. In this manner, FIRE's inclusion of the social sciences in its research mission opened the door to research engagements and professional development for first-year students like Boytim, who often struggle to find these opportunities amongst CUREs developed for more traditional STEM-centered disciplines.

\section{Research Experience \& Professional Development}

As both a student and peer mentor in FIRE Sustainability Analytics, Boytim was deeply immersed in the authentic methods and broadly relevant work of applied economics. She recalls that:

I experienced a steep learning curve using $\mathrm{R}$, the computer programming language, to analyze and merge meta-datasets as a key part of our methodology. Dr. Page was understanding of the varying levels of expertise amongst his students and, for me, provided guidance to help improve my programming competency. As a mentor, Dr. Page was a great judge of how much room to leave for us to work through challenges on our own before stepping in to provide 
support. While difficult and often frustrating at times, working through trial-and-error independently or with peers taught me how to be self-reliant in a research setting. This gave me a great sense of self-confidence that helped me advance as a researcher.

Boytim went on to report that research experience and professional development were simultaneous and related outcomes of FIRE program participation. She states that:

FIRE accelerated professional development for me by fostering key skills early on in my college experience. As a student researcher in the Sustainability Analytics Lab, we were expected to spend a minimum number of hours in the lab to complete our work in a timely manner. Being able to set a weekly lab schedule for myself around my courses and hold myself accountable allowed me to develop a mature, professional independence. Additionally, FIRE taught me how to think critically, to analyze data, to communicate information in different ways to different people, to write scientifically, and to work effectively both independently and with peers, among other skills. When I faced a challenge during my research, I was often encouraged to work independently or with peers to find possible solutions to overcome the hurdle rather than immediately submit to my faculty advisor. This fostered a sense of selfreliance that has helped me to this day in various leadership roles.

Success as Market Professional

Boytim is currently a director with Etna Community Organization (ECO), overseeing the planning, implementation, execution, and evaluation of ECO's community development initiatives. In this role, she is responsible for a broad range of logistical, operational, and community-based responsibilities requiring high levels of critical thinking, collaboration, and professionalism. She reports:

The skills that I developed through FIRE have been instrumental in my professional success as the leader of a small community-based nonprofit organization. My position, by nature, requires me to take on a diverse array of responsibilities both to further our mission and to keep the organization operating. Balancing workload, budgeting time to ensure productivity, and holding myself accountable, as the only staff member of the organization, are mandatory to accomplishing the organization's goals, just as it was in FIRE.

Boytim reports that FIRE was central to the development of both hard and soft skills that have contributed to her professional success. With respect to her current position, she states:

Many different stakeholders are involved in the community planning process of my work, including the municipal government, businesses, community groups, residents, and external partners. Having to work collaboratively with my FIRE peers of different backgrounds in a mature, respectful manner to accomplish our research goals has helped me successfully navigate this present work scenario. The organizational skills, the ability to work both independently and collaboratively, and the overall professionalism that were stressed in FIRE have also helped me succeed in my current position.

Summarily, Boytim communicated that FIRE was central to her professional development during her time as an undergraduate at UMD. She also shared: 
At the end of the day, the full depth and breadth of lessons, and skills learned from FIRE that have helped me achieve success are wide and far-reaching. I can assuredly say that, without FIRE, I would not have been able to grow and advance as quickly or successfully in my current professional field. These particular skills that have helped me succeed in my current professional position include organization, interpersonal relationship-building, communication, analytical reading and writing, accountability, professionalism, collaboration, time management, problem-solving, patience, diligence, and more. Without FIRE, I do not think that I would be as confident in my leadership role, as effective in communicating ideas and working collaboratively with others, or as diligent to hold myself accountable and manage my time and work efficiently.

\section{References}

American Association for the Advancement of Science [AAAS]. (2011). Vision and change in undergraduate biology education: A call to action. Retrieved May 6, 2020 from https://visionandchange.org/about-vc-a-call-to-action-2011

Auchincloss, L. C., Laursen, S. L., Branchaw, J. L., Eagan, K., Graham, M., Hanauer, D. I., Lawrie, G., McLinn, C. M., Pelaez, N., Rowland, S., Towns, M., Trautmann, N. M., Varma-Nelson, P., Weston, T. J., \& Dolan, E. L. (2014). Assessment of course-based undergraduate research experiences: A meeting report. CBE_Life Sciences Education, 13(1), 29-40. https://doi.org/10.1187/cbe.14-01-0004

Beckham, J. T., Simmons, S. L., Stovall, G. M., \& Farre, J. (2015). The Freshman Research Initiative as a model for addressing shortages and disparities in stem engagement. In M. A Peterson \& Y. A Rubinstein, Directions for Mathematics Research Experience for Undergraduates (pp. 181-212). World Scientific. https://doi.org/10.1142/9789814630320_0010

Brownell, S. E., Kloser, M. J., Fukami, T., \& Shavelson, R. (2012). Undergraduate biology lab courses: Comparing the impact of traditionally based, "cookbook" and authentic researchbased courses on student lab experiences. Journal of College Science Teaching, 41(4), 36.

Elgin, Sarah C. R., Gita Bangera, Sean M. Decatur, Erin L. Dolan, Laura Guertin, Wendy C. Newstetter, Elvyra F. San Juan, et al. 2016., "Insights from a Convocation: Integrating Discovery-Based Research into the Undergraduate Curriculum.” CBE_Life Sciences Education, 15(2): 1-7. doi: 10.1187/cbe.16-03-0118

Killion, P., \& Page, I. (2016). University of Maryland's First-Year Innovation and Research Experience (FIRE) encourages student participation in policy-based research. Council on Undergraduate Research Quarterly, 36(3), 47.

Killion, P., Page, I., \& Yu, V. (2019). Big-data analysis and visualization as research methods for a large-scale undergraduate research program at a research university. Scholarship and Practice of Undergraduate Research, 2(4), 14-22. https://doi.org/10.18833/spur/2/4/7

Linn, M. C., Palmer, E., Baranger, A., Gerard, E., \& Stone, E. (2015). Undergraduate research experiences: Impacts and opportunities. Science, 347(6222), 1261757. https://doi.org/10.1126/science.1261757

National Academies of Sciences, Engineering, and Medicine. (2017). Undergraduate research experiences for stem students: Successes, challenges, and opportunities (J. Gentile, K. Brenner, \& A. Stephens, Eds.). National Academies Press. https://doi.org/10.17226/24622

National Association of Colleges and Employers. (n.d.). Career Readiness Defined. Retrieved May 6, 2020, from https://www.naceweb.org/career-readiness/competencies/career-readinessdefined. 
Rodenbusch, S. E., Hernandez, P. R., Simmons, S. L., \& Dolan, E. L. (2016). Early engagement in course-based research increases graduation rates and completion of science, engineering, and mathematics degrees. CBE_Life Sciences Education, 15(2), ar20. doi: 10.1187/cbe.16-03-0117

The University of Maryland. (n.d.). The First-Year Innovation \& Research Experience. Retrieved May 6, 2020, from https://www.fire.umd.edu

University of Texas at Austin, College of Natural Sciences. (n.d.). Freshman Research Initiative. Retrieved May 6, 2020, from https://cns.utexas.edu/fri 